\title{
Shapes and Pole Orientations of Asteroids (360) Carlova and (209) Dido
}

\author{
Xi-Liang Zhang $\cdot$ Li-Yun Zhang $\cdot$ Jun Xu
}

Published online: 31 July 2008

(C) Springer Science+Business Media B.V. 2008

\section{Erratum to: Earth Moon Planet (2007) 101(3-4) 189-194 DOI 10.1007/s11038-008-9229-z}

Unfortunately some errors occurred in the publication of this paper. The corrections are detailed below:

Within the abstract, the values of $\mathrm{a} / \mathrm{b}$ and $\mathrm{b} / \mathrm{c}$ for asteroid (360) should be 1.52 and 1.5 instead of $1.52^{\circ}$ and $1.5^{\circ}$.

The values of $\mathrm{a} / \mathrm{b}$ and $\mathrm{b} / \mathrm{c}$ for asteroid (209) should be 1.3 and 1.1 instead of $1.3^{\circ}$ and $1.1^{\circ}$.

In the last sentence of Section 4 (Results), paragraph 2, the text should be 1.52 and 1.5 instead of $1.52^{\circ}$ and $1.5^{\circ}$.

In the second sentence of Section 5 (Discussion), the text should be 1.3 and 1.1 instead of $1.3^{\circ}, 1.1^{\circ}$.

The online version of the original article can be found under doi:10.1007/s11038-008-9229-z.

X.-L. Zhang $(\bowtie) \cdot$ L.-Y. Zhang · J. Xu

National Astronomical Observatories, Yunnan Observatory, Chinese Academy of Sciences,

Kunming, Yunnan 650011, China

e-mail: zhangxiliang@ynao.ac.cn 